\title{
EDUCAÇÃO E CULTURA POPULAR: RESULTADO DE INVESTIGAÇÕES NAS ESCOLAS DO CEMESSC
}

\author{
Marli de Oliveira Costa ${ }^{1}$
}

\section{INTRODUÇÃO}

Esse texto aborda o resultado de um estudo sobre o tema cultura popular, realizado em 2014 ao acervo do Centro de Memória da Educação do Sul de Santa Catarina- CEMESSC, em meio virtual. Tal Centro é acessível por meio da página www.bib.unesc.net/muesc/muni 07.php. O CEMESSC é um dos trabalhos desenvolvidos pelo Grupo de Pesquisa História e Memória da Educação - GRUPEHME, vinculado a Universidade do Extremo Sul Catarinense- UNESC.

Compreende-se o conceito de cultura popular a partir do que enuncia Santos (1986 p. 54):

\begin{abstract}
[...] As culturas populares são tentativas de classificar as formas de pensamento e ação das populações mais pobres de uma sociedade, buscando o que há de específico nelas, procurando entender a sua lógica interna, sua dinâmica e, principalmente, as implicações políticas que possam ter. Manifestações culturais dessas classes. Manifestações diferentes da cultura dominante, que estão fora de suas instituições, que existem independentemente delas, mesmo sendo suas contemporâneas. (SANTOS, 1986, p. 54).
\end{abstract}

Desse modo entende-se que, a cultura do povo pôde e pode ter nas escolas uma forma de se manter, garantindo o direito à memória das novas gerações. Compreende-se que o risco do desaparecimento de saberes utilizados no passado apresenta-se como uma ameaça ao direito da produção cultural construídos pela sociedade, ao direito a memória histórica, garantido pela Constituição brasileira no art 215 - "O Estado garantirá a todos o pleno exercício dos direitos culturais e acesso às fontes da cultura nacional, e apoiará e incentivará a valorização e a difusão das manifestações culturais"

\footnotetext{
${ }^{1}$ Doutora em Educação pela Universidade Federal do Rio Grande do Sul. Professora dos cursos de história e Pedagogia da Universidade do Extremo Sul Catarinense-UNESC. moc@unesc.net.
} 
Esse trabalho oferece visibilidade à cultura popular no âmbito escolar, garantindo dessa forma reflexões acerca do patrimônio educativo, ou seja, o que foi preservado no âmbito da educação escolar. O objetivo do estudo foi identificar nos documentos do acervo do CEMESSC, como as escolas trabalhavam os diferentes elementos da cultura popular, identificando transformações e permanências.

\section{METODOLOGIA}

A metodologia utilizada foi a análise documental do acervo digitalizado das escolas do CEMESSC, agrupando em tabelas, o nome da escola, o tipo de documento como atas, fotografias, jornais escolares ou outros que registra a manifestação cultural e a identificação dessa manifestação. $O$ período investigado foi do documento mais antigo de cada escola (em torno dos anos de 1930) á 1979, data limite das digitalizações realizadas para compor o CEMESSC. Para compreender e identificar os registros como pistas de trabalho com cultura popular foi necessário revistar os conceitos de cultura popular relacionado ao direito à memória, patrimônio cultural e cultura material escolar.

Viñao Frago (2000) coloca que a cultura escolar apresenta-se como um conjunto de ideias, princípios, critérios, normas e práticas sedimentadas ao longo do tempo das instituições que trabalham com educação das novas gerações. Pois o interior dessas instituições são produzidas formas de pensar e de agir, que envolvem aqueles que participam das práticas escolares "estratégias e pautas para desenvolver tanto nas aulas como fora delas", atitudes, modos de vida e de pensar, materialidade física, hábitos, objetos e ritos escolares. Como cultura material escolar entende-se o conjunto de artefatos, cuja existência, uso e significado estão vinculados historicamente ao processo de escolarização. Nessa investigação o conjunto dos artefatos está presente de forma virtual no acervo do Cemessc.

Embora o formato se apresente como virtual, entendemos que em função de seu conteúdo o acervo dessas escolas constitui como patrimônio cultural, pois o conceito de Patrimônio Cultural diz respeito a todas as relações que apresentam um significado especial, afetivo, político ou social para um 
lugar. O Patrimônio Cultural pode ser dividido em bens tangíveis e bens intangíveis, ou seja, na cultura material e imaterial. Compreendemos por bens tangíveis ou Patrimônio material monumentos, edifícios construídos pelos humanos ou rios, vales, montanhas, matas - erguidos no processo natural desse planeta, bem como, objetos, artefatos e documentos. (Lemos, 1987). O Patrimônio Imaterial diz respeito aos saberes e práticas de uma comunidade. Pode ser dividido em: saber fazer, celebrações, expressões e lugares. Nesse sentido os documentos investigados podem ser caracterizados como patrimônio material e seu conteúdo como patrimônio imaterial.

O CEMESSC abriga o acervo de 27 escolas sendo 11 nos municípios da Associação dos Municípios da Região Carbonífera - AMREC, 11 da Associação dos Municípios do Extremo Sul Catarinense - AMESC e cinco da Associação de Municípios da Região de Laguna - AMUREL.

Compreende-se como elementos da cultura popular, alguns jogos, brincadeiras, folguedos, danças, festas, dizeres, saberes e também alguns artesanatos. As culturas populares acima citadas fazem parte do patrimônio imaterial. A cultura como sugere Canclini (2000), "um processo social de produção".

A pesquisa envolveu o trabalho de seleção e organização (Certeau, 2002) dos documentos por escola que apresentam pistas dessa cultura nos processos pedagógicos, quantificando as práticas em uma tabela.

\section{RESULTADOS}

As 27 escolas que compõem o CEMESSC são as escolas estaduais mais antigas e de relevância no sul do estado de Santa Catarina, são elas: Treviso- E.E.B. Udo Deeke, Cocal do Sul- E.E.B. Padre Schuller, Orleans E.E.B. Costa Carneiro, Içara- E.E.B. Salete Scotti dos Santos, Lauro MullerE.E.B. Visconde de Taunay, Morro da Fumaça- E.E.B. Princesa Isabel, Nova Veneza- E.E.B. Julieta Torres Gonçalves, Siderópolis- E.E.B. José do Patrocínio, Urussanga- E.E.B. Barão do Rio Branco, Criciúma- E.E.F. Professor Lapagesse e Forquilhinha- E.E.F. Ângelo Izé situadas na região da AMREC. Araranguá- E.E.B. Castro Alves, Jacinto Machado- E.E.B. Jacinto Machado, Maracajá- E.E.B. Manoel Gomes Baltazar, Meleiro- E.E.B Meleiro, São João do 
Sul- E. E. B Professora Maria Solange, Praia Grande- E.E.B Lopes de Borba, Sombrio- E.E.B. Bulcão Viana, Passos de Torres- E.E.B. Gov. Ildo Meneghetti, Turvo-, Jorge Schutz Ermo- E.E.F. Pedro Simon, Timbé- E.E.B., Timbé do SulNa região da AMESSC; Jaguaruna- E.E.B. Marechal Francisco Carlos da Luz, Imaruí- E.E.B. Professora Eulina Heleodoro Barreto, Imbituba- E.E.B. Henrique Lage, Braço do Norte- E. E. B Dom Joaquim e Tubarão- E.E.B. Hercílio Luz na região da Amurel.

Ao todo foram investigados 2.256 documentos, sendo que desses, 139 documentos apresentaram conteúdos acerca da cultura popular que envolviam atividades dessa cultura nas escolas.

Percebeu-se pela análise dos documentos que a cultura popular como manifestação de uma das camadas da população foi incorporada nas atividades pedagógicas por meio das datas comemorativas e outras festividades, bem como, alguns textos publicados em jornais escolares e nos planos de aula de artes e de educação física.

Os jornais escolares publicados de forma manuscrita ou datilografada, mostram poesias, textos de alunos, problemas de matemática e também alguns desenhos relativos as datas comemorativas e/ou temas do folclore brasileiro. Em algumas escolas não foram encontrados jornais, ou esses não foram guardados.

As fotografias se apresentaram como documentos especiais que evidenciam essas práticas, pois pelos retratos escolares é possível identificar apresentações que reportam as festas juninas, teatros e danças. Foi possível também identificar alguns jogos praticados na educação física referentes as brincadeiras da cultura popular, como: corrida do saco, roda, campeonatos, etc. $O$ acervo fotográfico das escolas é o documento mais abundante com relação a participação dos alunos e alunas nessas atividades.

Algumas atas de reuniões pedagógicas mencionam o planejamento de festividades que envolveram danças e brincadeiras como: boi-de-mamão, pau-de-fita, quadrilhas, cantigas e outros. No entanto, esses registros são superficiais, indicando apenas a realização das atividades não, a compreensão dos educadores acerca da importância da continuidade de práticas pedagógicas relacionadas a essa cultura. 
As datas dos documentos vão da década de 1930 até o final da década de 1970. Com relação às festividades e danças, percebeu-se que algumas escolas não apresentaram registro acerca dessas atividades nos documentos guardados no CEMESSC. Quanto ao registro de brincadeiras e brinquedos, também encontramos escolas que não indicam essas atividades na documentação investigada. Tal constatação não significa que as escolas não trabalharam tal cultura e sim, que a cultura do descarte considerou irrelevante arquivar tais manifestações.

Percebeu-se também que muitas das atividades foram realizadas em função de orientação superior, ou seja, normativas enviadas pelo Estado sugeriam a realização de atividades relacionadas a cultura popular, nenhum dos documentos apresentava a discussão do porque realizá-la. Sendo que percebe-se 0 entendimentos dessa cultura como uma cultura menor, relacionada a ideia de folclore e não de cultura. No entanto, ao se fazer presente nessas escolas na temporalidade investigada, pode-se inferir que as escolas de alguma forma realizaram o papel de serem guardiãs dessa cultura, repassando algumas práticas as novas gerações.

Que manifestações são essas. Agrupamos algumas por estarem mais presentes nos documentos: Festas juninas, brincadeiras e brinquedos cantados, cantigas, dizeres e provérbios e outras.

\section{QUANTO AS FESTAS JUNINAS}

Dos 139 documentos com conteúdo investigados nas escolas, 112 apresentaram pistas de realização de festas juninas. Dentre os documentos, as atas de reuniões pedagógicas mostram o planejamento e a distribuição de tarefas que envolviam a parte culinária, as atrações e a decoração sendo que os estudantes eram responsáveis pelos números artísticos envolvendo quadrilhas, pau de fita e casamento de jeca. $O$ documento mais antigo que aponta para essa atividade data de 1962 e é da escola Princesa Isabel de Morro da Fumaça, são duas fotografias. O Centro Cívico Anita Garibaldi da Escola de Jacinto Machado registrou em suas atas a participação dessa associação na organização das festas juninas, na década de 1980. As Festas Juninas são consideradas integrantes da Cultura Popular, por ser realizadas 
em comunidades e envolvendo as comunidades, bem como, ser um ritual vivenciado por várias gerações. Elas foram incorporadas pelas escolas, mas surgiram em torno de Santos Padroeiros, como festas de capelas. As escolas investigadas abordam principalmente das Festas em honra a São João.

\section{QUANTO AS BRINCADEIRAS COMO PETECA, RODAS E BRINQUEDOS CANTADOS}

Dos 139 documentos com conteúdos, onze deles mencionam a realização de atividades de roda, brinquedos cantados e peteca. As informações datam de 1947 a 1973 e foram encontradas nos relatórios de Educação Física da professoras Iva Damiani da E.E.B. Barão do Rio Branco de Urussanga. Essas atividades eram desenvolvidas com as crianças até a $4^{\underline{a}}$ série. No Grupo Escolar Professor Lapagesse, de Criciúma também foi encontrada uma fotografia evidenciando a brincadeira de roda. Na EEB Castro Alves de Araranguá foi encontrado nos Relatórios da escola enviados ao Departamento de Educação do Estado de Santa Catarina em 1947, referente ao ensino de E. Física. E, no Relatório de Educação física, professora Leonilza dos Santos de 15/03/1972 da Escola de Maracajá. Além desses, O Jornal Escolar: O Estudante Orleanense da E.E.B. Costa Carneiro, registra uma atividade de matemática com bolinhas de gude em novembro de 1970 com um aluno do $2^{\circ}$ ano. Os brinquedos e as brincadeiras infantis passadas de geração a geração integram as culturas populares infantis. Alguns sofreram variações de acordo com o tempo e a região, no entanto, envolvem elementos culturais dessa camada da população. Pois como coloca Fantin:

Os jogos comuns presentes em diversas sociedades e culturas podem ser o terreno fértil do dialogo de crianças de culturas diversas. A brincadeira pode abrir a janela sobre o mundo, alargando horizontes e alimentando sentimentos de respeito à pluralidade para além de propostas educativas. (FANTIN, 2000, p.221).

As brincadeiras inventadas e reinventadas pelas crianças fazem parte das culturas populares infantis e apresentam-se como patrimônio imaterial dessa camada geracional da população. 


\section{QUANTO AS CANTIGAS, DIZERES, PROVÉRBIOS}

Dos 139 documentos, 13 mencionam cantigas, dizeres e provérbios. Esses conteúdos estão nos Jornais escolares publicados em algumas escolas, o mais antigo deles data de outubro de 1950 na E.E.B. Costa Carneiro, de Orleans. Os dizeres fazem parte da cultura popular e atravessaram os séculos. Assim, versos, adivinhações, provérbios e cantigas são passadas de geração a geração. Muitos desses versos sofrem modificações com o tempo mas, deixam permanecer o tom de brincadeira que motivou sua criação, trata-se pois da dinamicidade da cultura, que não é estática e está sujeita as diferentes necessidades de cada tempo e sociedade.

\section{QUANTO A OUTRAS MANIFESTAÇÕES}

Dos 139 documentos com conteúdo da Cultura popular 18 deles apresentam ainda indicações de: boi-de- mamão, notícias sobre o dia de finados, redação com o tema Circo e Carnaval, presença de sanfoneiros, figuras de personagens de lendas brasileiras como o Saci, comemorações sobre o Folclore e outras festas religiosas como o Corpus Christi. Todas essas indicativas mostram que de alguma forma a cultura popular era vivenciada nas escolas. Associada ao catolicismo ou as práticas pagãs, eram repetidas no ambiente escolar em um tempo circular, tempo do Carnaval, de dançar o boide- mamão. Muitas dessas expressões não são mais vivenciadas em comunidades e têm nas escolas um ancoradouro, isso é uma forma de ser lembrados. No entanto, a maioria ocorre apenas como repetição, não foi encontrado documento que aborde a preocupação em contextualizar, conhecer a história ou mesmo discutir com os alunos o porquê do trabalho.

\section{CONCLUSÃO}

Ao analisar a documentação das escolas foi possível identificar diferentes atividades pedagógicas em torno da cultura popular, percebendo a dinâmica da cultura que atualiza as manifestações populares, como por exemplo, a incorporação de elementos atuais nas danças típicas, visíveis nas 
fotografias. E, também o imbricamento da cultura de massa com a cultura popular, o que é percebido nas danças e nos chamados "shows" de valores.

Ainda, a presença de registros nos jornais escolares, que evidenciam diferentes letras de canções, que realizam bricolagens sendo a partir de uma canção folclórica. A pesquisa oportunizou constatar que todas as escolas investigadas guardaram algum documento que reporta essa atividade em algum momento da vida escolar. Percebe-se, no entanto, que a Cultura Popular aparece nos documentos dessas escolas em situações peculiares, prevalecendo, os eventos comemorativos, principalmente as festas juninas, associadas à tradição do catolicismo e em poesias e dizeres inscritos nos jornais escolares. Localiza-se também, nesses registros que a disciplina de educação física registrava essas atividades.

Em algumas escolas não foi possível identificar conteúdos, isso não significa que não eram trabalhados, mas que não foram registrados ou os registros não foram guardados. Anterior aos anos de 1950, com apenas uma exceção, não foi identificada nenhuma notificação dessa cultura nos documentos. De alguma forma, as escolas puderam garantir em parte o lugar de memória de brincadeiras, danças, folguedos e dizeres da cultura popular, veiculando-as as novas gerações. Pois como reflete Carlos Rodrigues Brandão (2008) Não devemos reforçar expressões como "esse homem não tem cultura nenhuma" ou "essa é uma gente sem cultura". Pois, "não são raras hoje em dia, como no passado, ações sociais derivadas de ideias que centram em um modo de ser ou em uma cultura toda a excelência, e desqualifiquem as outras" (BRANDÃO, 2008, p. 33). Trata-se do etnocentrismo, que ao longo do tempo não valorizou as manifestações da cultua popular.

\section{REFERÊNCIAS}

BRANDÃO, C. R. Viver de criar cultura, cultura popular, arte e educação. In: SALTO PARA O FUTURO. Cultura popular e educação. Brasília: TV ESCOLA/SEED/MEC, 2008. p. 25-38.

CANCLINI, N. G. O. Culturas hibridas. São Paulo: Edusp, 2000.

CERTEAU, Michel de. Capítulo II: Operação Historiográfica. In: A Escrita da História. Rio de Janeiro: Forense Universitária, 2002, p. 65-119 
FANTIN, Mônica. No mundo da brincadeira. jogo, brinquedo e cultura na educação infantil. Florianópolis: Cidade Futura, 2000. (6 exemplares 3.71 .397 f2 16n 2000).

LEMOS, Carlos. O que é Patrimônio Histórico. São Paulo: Brasiliense, 1987.

SANTOS, José Luiz dos Santos. O que é cultura - 16 ed.- São Paulo:

Brasiliense, 2006.- (Coleção Primeiros Passos;110).

VIÑAO FRAGO, Antônio. El espacio y el tiempo escolares como objeto histórico. Contemporaneidade e Educação. Instituto de Estudos da Cultura e Educação Continuada (IEC), Rio de Janeiro, n.7, 2000. 